\title{
Environmental decision-making: the influence of policy information
}

\author{
Clau DERMONT \\ University of Bern \\ Institut für Politikwissenschaft, Bern, Switzerland \\ Email: clau.dermont@ipw.unibe.ch \\ ORCID: 0000-0001-5456-8935
}

\begin{abstract}
The success of technological development depends on citizens' social acceptance, whereas several challenges related to the understanding of citizens' reactions to renewable energy and its policies are identifiable. Most importantly, the gap between general attitudes toward the environment and specific voting behaviour regarding environment-friendly policy proposals calls for an explanation of how a policy's design causes citizens who might otherwise support environmental measures to express opposition in direct democratic votes. Therefore, how policy design and policy information impact opinion formation is investigated. Salient aspects are identified and the different types of information or qualifications that may cause opposition are considered. This new approach reveals that citizens, in environmental decision-making, do indeed consider policy design and policy information, which they regard as conditions for support, and that the type of policy information matters since citizens do not consider all of the policy details when they make decisions.
\end{abstract}

Keywords: public decision-making; environmental measures; policy information; voting; direct democracy; renewable energy policy; Switzerland 


\section{Introduction}

In the aftermath of the Fukushima incident and the Paris climate accord, many countries debated policies geared toward a transition from the nuclear and fossil energy era to renewable energies. For example, in 2011, the Swiss government expressed the aim to discontinue dependence on nuclear energy by 2050 by replacing the approximately $40 \%$ of nuclear energy in electricity production with renewable energies. The challenge for the political elite in this and similar processes is to select suitable policies to reach this target, as there are many possibilities. As a second challenge, the question arises as to how the public will react to such targets and policy proposals, which Wüstenhagen et al. (2007) refer to as 'social acceptance'. Social acceptance refers to the favourable reaction of the public, markets and political actors towards renewable energy technologies and policies, and is considered a necessary condition for the success of those technologies and policies. Policies aimed at climate change or promotion of renewable energies therefore need the support of the public, especially if voters have the opportunity to decide on the proposed policy through direct democratic means.

Here, I will focus on citizens' voting on the future of energy policy in Switzerland. While the call to let the people decide resonates in the growth of direct democratic decisions in many countries (Altman 2010), Switzerland is still an ideal case to investigate how individuals decide and vote on policy instruments due to the wealth of direct democratic decisions. Moreover, in May 2017, the citizens of Switzerland voted on a new energy law (Swiss Confederation 2016), which sets the guidelines for the development of the energy sector. The law stemmed from intense debate on the pros and cons of the policy targets and the design of the policy itself, essentially confirming the Swiss government's aim to phase out nuclear power triggered by the critical event in Fukushima 2011 (Bernardi et al. 2018). This vote is therefore a prime example of social acceptance (Wüstenhagen et al. 2007).

When focusing on citizen decision-making in regard to environmental issues, researchers should address several issues. First, in environmental decisions, the gap between general opinion and specific behaviour - known as 'the value-action gap' (Bell 
et al. 2005, Kollmuss and Agyeman 2002) - poses a challenge for capturing how citizens will vote in a specific proposal even if they are in favour of the general target. Assessing the social acceptance of intended policies therefore depends on the possibility to validly measure how citizens will react to the political elite's propositions. One explanation for the gap is 'qualified support,' whereby individuals support a target only conditionally -i.e., if the specifics of a policy correspond to their preferences (Bell et al. 2005). Second, in order to reflect on this gap, the question arises as to which aspects of a policy citizens consider in opinion formation -i.e., the qualifications or conditions that policies need to fulfil. Conceptually, I will build on insights on opinion formation and investigate how citizens consider substantial policy information when deciding on environmental measures (Bullock 2011, Boudreau and MacKenzie 2014). Third, as encompassing proposals such as a new energy law include multiple elements that could all incite rejection of a policy if those conditions fail to meet the expectations of some supporters, I will investigate this multidimensionality of decision-making more thoroughly. An example of policies with multiple elements is proposals which include both promotional measures for renewable energies and restrictions for nuclear power. As such, policymakers combine various aspects into one decision, which can potentially lead to conflicts of interest. From a methodological point of view, this contribution therefore applies multifactorial experiments modelled after actual decisionmaking situations (Hainmueller et al. 2014).

I therefore investigate how decision-making concerning energy policy depends on the specific design of a policy. Specifically, how does policy information influence the support for renewable energy policy? To address the mentioned challenges, I analyse a conjoint experiment implemented through a large-scale representative survey in Switzerland. A conjoint experiment is an approach to investigate preferences about objects that vary in multiple aspects and enables us to assess which attributes or elements of, e.g., a policy influence support for this policy (Hainmueller et al. 2014). The multifactorial setup considers the multidimensionality of policy proposals and therefore informs us how the specific aspects or conditions of a policy drive citizens' decisions and provides insight into aspects that are potentially more salient. A survey experiment focused on citizens' preferences toward an energy policy is better able to 
capture how voters might actually vote on a specific proposal (Dermont et al. 2017) compared to asking direct questions about their preferences regarding the environment. Lastly, this approach allows for an analysis of which citizens are more likely to consider substantial policy information and which citizens focus on certain key elements of policies.

\section{Theory}

In previous decades, developments in energy politics yielded several highly conflicting and emotional debates. Protests - especially against siting projects, such as nuclear power plants or large hydroelectric plants - eventually led to abandoned sites Kaiseraugst (AG) and the Greina Plateau (GR) in Switzerland. While those two cases are quite specific processes, they illustrate the relevance of social acceptance for technologies and energy policy targets (Wüstenhagen et al. 2007). Effective policy change, regardless of the target, needs the support of citizens. If citizens act as decision-makers and therefore as veto players (Tsebelis 2002) through direct democracy, their reaction toward proposals such as a new energy law (Swiss Confederation 2016) is central and policymakers interested in the realization of targets, such as those related to climate policies, should consider those reactions (Bayulgen and Ladewig 2017, Szulecki 2018).

\section{Specificity of policies}

What factors cause citizens to support or reject an environmental policy? In environmental decisions, the discrepancy between attitudes and actions limits our understanding of voting behaviour; scholars also refer to it as the 'value-action gap' or 'social gap' (Bell et al. 2005, Bell et al. 2013, Kollmuss and Agyeman 2002). Although public opinion usually favours renewable technologies, environmental protection, and 'green' solutions, the gap between this articulated general acceptance and the voters' rejection of tangible policy measures or particular energy sources is highly relevant for policymakers in attaining their targets. As Bell et al. (2005, Bell et al. 2013, DevineWright 2005) suggested, one explanation for the social gap between general attitudes 
and actual behaviour is 'qualified support': people generally support wind energy but with certain limits or controls in mind. Therefore, in an actual decisional situation, citizens would reject a proposal lacking the qualifications or conditions they expect regardless of their general support for wind energy. Similarly, Hobman and Ashworth (2013, p. 865) reported that citizens reacted to simple information in evaluation of energy sources: support changes significantly when researchers provide respondents with factual information about costs or emissions, which, for example, lead to lower support for cost-intensive energy sources (see also van Rijnsoever et al. 2015).

Hence, the decision to support a proposal is contingent on the proposal itself, whereby the exact design of a policy could be a relevant explanation of why (general) attitudes and (specific) behaviour diverge (Dermont et al. 2017). Voters thus reject policies that fail to include the qualifications they require, although they would support the general target of a policy. A campaign providing citizens with more detailed information prior to a popular vote could thus incite a more systematic examination of the issue at hand (Hobman and Ashworth 2013, van Rijnsoever et al. 2015), which reduces their support for environmental measures as the corresponding costs, behavioural restrictions, or technocratic hurdles beat the appeal of environmental gains.

Researchers therefore need to carefully assess how to explicitly capture the reaction they want to analyse; tangible research on support for environmental policies needs to consider the specific design of a policy (Dermont et al. 2017). Most importantly, providing respondents with the pertinent information on a policy increases the validity of their responses, as they do not simply answer generally but rather consider the context of a proposal, as Bell et al. (2005) suggested for qualified supporters.

\section{Opinion formation under consideration of information}

What influence does information have on voting in direct democracy? According to dual-process theories on attitudes, citizens process information heuristically or systematically (Eagly and Chaiken 1993, Petty and Cacioppo 1986). The heuristic processing of information reflects simple decision-making based on cues such as a party or government position. The systematic processing of information, i.e. the examination of arguments and details of a policy, is more demanding and thus more appealing 
to voters who are highly involved and/or interested in politics or the issue at stake (Kriesi 2005, Nai 2010). In the Swiss setting, in which citizens participate every few months in direct democratic decisions, Kriesi (2005) and Colombo and Kriesi (2017) have argued that the systematic processing of information plays a key role in opinion formation. Essentially, consideration of arguments and policy details addresses the issue of qualified responses, as Bell et al. (2005) suggested. Voters focus on the specifics of policies instead of voting for environmental measures regardless of the details.

A promising approach to better understanding systematic processing involves presenting individuals with policy information and observing how this information affects their decision-making. As Bullock (2011) and Boudreau and MacKenzie (2014) have shown, policy information matters for decision-making, even when compared with heuristics. However, the approaches to examine the influence of policy information differ. Boudreau and MacKenzie (2014) use rather general frames, such as the reduction of state correctional costs by 'tens of millions of dollars each year' (see supplemental material in Boudreau and MacKenzie 2014). Yet, Bullock (2011, p. 498) criticized these kinds of 'short and vague' policy descriptions in former research, since he regards detailed messages as more influential than vague frames. In his experiments, Bullock (2011) used newspaper articles that described either 'conservative' or 'liberal' changes in health care in which several details, such as coverage, co-pay, disability coverage, and costs, varied between the status quo and the proposed changes. Bullock's (2011) approach, i.e. detailing the specifics of a proposal, is a tangible approach to consider the 'qualifications' of support, as Bell et al. (2005) suggested, while the broader approach that Boudreau and MacKenzie (2014) applied would likely fail to capture the possible qualifications of a policy, which kindle rejection.

Since the liberal or conservative versions of Bullock's (2011) study have fixed policy details, the individual effects or salience of the policy details are not comparable. Thus, Bullock (2011) only compared the overall effects of the policy changes of the more liberal and more conservative alternatives to the status. However, each of these details in policy design could be the reason why a voter changes her or his opinion on an issue. Notably, Hobman and Ashworth (2013) tested the influence of costs and emissions separately, thus enabling separation of the effects of two possible treatments 
and, associatively, the determination of which treatment might be more salient. Van Rijnsoever et al. (2015) went a step further by considering multifactorial treatments and five attributes of energy sources, adding factors such as spatial impact and security of supply. By building on the theory of systematic opinion formation, the expectation is therefore that voters consider each detail as relevant policy information or as a qualification, rather than only the overall condition such as in Bullock (2011). Each detail has the potential to be the relevant information or qualification that tips a voter's decision from yes to no and vice versa, especially for less opinionated citizens. An approach to considering multiple policy details at the same time is a conjoint experiment. A conjoint setup presents respondents with multiple information and can assess the influence of each policy detail separately (Hainmueller et al. 2014). Conceptually, such a setup allows for a further testing of the assumption of Bell et al. (2005) regarding qualified supporters. It also extends our understanding of the influence of policy design in environmental decisions. Moreover, it develops the insights of Bullock (2011) and others regarding the influence of policy information on decision-making; it more precisely analyses what affects the support of policies. In the following section, I discuss the factors that influence decision-making regarding the issue at hand.

\section{Influence of policy information}

Building on the general research on the influence of policy information ${ }^{1}$ on decisionmaking (Boudreau and MacKenzie 2014, Bullock 2011) and on the more specific factors influencing the assessment of energy sources (Hobman and Ashworth 2013, van Rijnsoever et al. 2015), a question arises about how information influences the reaction toward policies, which is my focus here.

Various studies have analysed how citizens voted on environmental policies, mainly with respect to Switzerland (Bornstein and Lanz 2008, Bornstein and Thalmann 2008, Halbheer et al. 2006, Stadelmann-Steffen 2011, Thalmann 2004) and the United States (Deacon and Shapiro 1975, Kahn and Matsusaka 1997, Wu and Cutter

\footnotetext{
1 The notion of 'policy information' stands for information, descriptions, and arguments regarding how a policy is designed, which instruments are included (such as taxes vs. bans), and the effect of a policy. Here, I consider the details and aspects of a policy as policy information, which I also use as conjoint attributes in the implementation of the experiment.
} 
2011). The literature attributed the main argument for acceptance or rejection of new environmental policies to the perceived costs of a proposal and cost-benefit considerations; voters will choose the option that leads to fewer costs for them (Bornstein and Thalmann 2008). Additionally, the type of policy instrument is relevant. For example, Stadelmann-Steffen (2011) reports that citizens prefer bans and rules to incentives or market-based policies. The reason might be a 'cost illusion' since bans or rules exhibit no direct economic costs, whereas 'individual costs are better visible with incentivebased instruments' (Stadelmann-Steffen 2011, p. 497f). Those aspects - costs, benefits, and instrument choice - pertain to policy information that likely belongs to the systematic path of opinion formation, i.e. provisions of a policy that might incite the opposition of voters who would otherwise generally favour environmental action (Bell et al. 2005). Similarly, although they focused on energy sources rather than policies, Hobman and Ashworth (2013, p. 864) considered costs and emissions of energy sources as systematic factors for decision-making.

Gathering from this, one central aspect for future energy policy decisions is costs and perceived costs, which work as conditions leading to the rejection of policies even if voters are generally in favour of the formulated target. The first two hypotheses regarding systematic processing are thus as follows:

Hypothesis 1a: Higher costs reduce support for environmental measures.

Hypothesis 1b: Policy instruments with less obvious direct costs raise support for environmental measures.

\section{Moderation of systematic processing}

If voters consider policy information as a part of their decision-making process, corroborating the qualified support explanation of Bell et al. (2005) for the social gap, the follow-up question would be which voters react to policy information and are thus qualified supporters. In dual-process theory, researchers have claimed that the volition to follow the cognitively demanding systematic path is dependent on the characteristics and involvement of the individual. As Chaiken (1980) has argued, an individual's involvement in an issue, or how important she perceives the consequences of her choice, moderates the strategy she employs. In the Swiss context, Kriesi (2005) has 
considered the influence of general (level of education) and issue-specific political competence as well as political interest as indicators of motivation, which lead to a higher likelihood of making use of arguments when deciding how to vote. With respect to the choices that voters make, Nai (2010) focused on knowledge of the issue at stake and spontaneous reasons as measures of political competence and how relevant a voter considers the ballot to be. Thus, individuals with high general and specific political competence and knowledge, political interest, and issue involvement and who feel the need to substantiate their responses are more likely to use more substantial policy information.

The more involved a respondent is, the more he will be attentive to more specific details - such as the type of instrument-of a policy. Less involved respondents will likely focus on the less demanding details of a policy that facilitate decision-making in the absence of cues. Two perspectives are relevant for evaluating how individual characteristics might moderate the use of policy information in the decision-making process. First, individual characteristics can affect the extent to which respondents distinguish between varying policies, i.e. engage with the decision situation. Second, individual characteristics can influence the salience of policy information, so certain individuals may be more susceptible than others to aspects such as costs. Since the expectation is to be able to confirm the results of Kriesi (2005) and Nai (2010) for the Swiss context and the insights into partisanship, prior attitudes, and knowledge of previous studies such as those that Bullock (2011) and Boudreau and MacKenzie (2014) carried out, the following hypotheses corroborate their conclusions for energy policies:

Hypothesis 2a: More involved individuals have a larger variance in their support for environmental measures since they engage more systematically in the decision-making process.

Hypothesis 2b: For less involved individuals, the effect of higher costs on their support for environmental measures is larger.

Hypothesis 2c: For less involved individuals, the effect of policy instruments with less obvious direct costs on their support for environmental measures is smaller.

The first hypothesis generally expects a relation between higher involvement and more systematic processing. The second and third hypotheses suggest that the type of 
policy information (i.e., the condition) that plays a role in systematic processing depends on involvement. Essentially, the assumption is that direct costs are more relevant with lower involvement than indirect, less perceivable costs (Stadelmann-Steffen 2011).

\section{A Survey Experiment}

For the methodological approach, I follow Hainmueller et al. (2014) by applying a randomized conjoint design to present respondents with varying policy information. Researchers have previously conducted experiments on individual preferences in environmental decision-making (van Rijnsoever et al. 2015), but these experiments have until now mainly focused on economic aspects such as consumer choices. Recently, Hainmueller et al. (2015) have shown that the results of hypothetical choices in conjoint experiments come close to how voters actually voted in the real world (namely, in citizenship naturalization referendums in Switzerland), which is a strong argument for the external validity of stated preference experiments. Moreover, Häusermann $e t$ al. (2015) and Bechtel and Scheve (2013) have focused on policies, namely pension schemes and global climate agreements.

The advantage of conjoint experiments is the simultaneous consideration of several policy details (or attributes) that vary for each policy proposal. Instead of focusing on one single, suggested frame or on fixed alternatives (Boudreau and MacKenzie 2014, Bullock 2011), a conjoint setup presents respondents with multiple information and can separately assess the influence of each policy detail (Hainmueller et al. 2014). Since each respondent repeatedly makes the same hypothetical decision, conjoint experiments enable two insights: first, the policy information or condition that drives the response and, second, the respondents who consider the policy information presented to them. In the present study, respondents participated in a conjoint experiment on support for the promotion of renewable energy. The question text asked respondents to envisage their decision as a hypothetical vote that would occur on the following Sunday. From seven paired concepts, each respondent answered which concept of each pair they would choose given a confrontational vote and how likely they would 
support each proposal. This approach corresponds to a voting process where the government presents a counter-proposal to a popular initiative and the ballot asks citizens whether they support each proposal separately,,$^{2}$ and which proposal the majority would want implemented if both proposals received a majority.

The conjoint experiment on renewable electricity policies varies regarding seven attributes (policy information): the promoted energy source, the policy instrument, the instrument's funding, the running time of the instrument, the additional monthly cost per household, exceptions for energy-intensive industries, as well as the handling of existing nuclear power plants (see Supplemental Online Material). The setup employs randomized treatments and attribute order. The randomization excluded illogical policy combinations (such as a general tax coupled with a redistribution, which has no effect on energy policy), and kept the attributes of the policy measure and funding in the same order and together for all the responses. The full setup of the experiment and the introduction are available in the supplemental material, Figure A1 in the Appendix documents an exemplary setup of the question.

Although an experiment will likely never have the same consequences as a real vote, and therefore has advantages mainly with respect to internal rather than external validity (McDermott 2011), a conjoint design and a non-fictional issue offer ideal conditions to analyse voter decision-making for two reasons. First, decision-making based on a conjoint table, i.e. based on key expressions, corresponds quite closely to voters' real-world decision-making (Hainmueller et al. 2014). It is likely that many citizens are not profoundly informed about the proposal at stake and instead base their vote on several key policy aspects mentioned in the campaign (and the party positions on these points, Kriesi 2005, 2012). In this sense, the effect of the abstraction of a conjoint table likely corresponds to the mentioning of the main issues and characteristics of a policy that arise during a campaign, which citizens eventually weigh when they make their decision. Second, the non-fictional issue, which the media and politicians regularly debated prior to the analysed vote, suggests that respondents are familiar with the issue - at least to a certain extent. Also, Swiss citizens vote approximately four

\footnotetext{
2 Citizens especially have the opportunity to support or reject both simultaneously. In other words, it is not necessary to vote 'yes' for one of the proposals. Moreover, even if a citizen rejects both proposals, she or he can still express her or his preference in the tiebreaker.
} 
times a year for federal matters, and they recently decided on complex matters such as immigration restrictions, pension schemes, tax reforms, transportation, and public media. Swiss voters therefore ty pically decide on far-reaching policies. Moreover, conjoint experiments provide respondents with multiple reasons to justify a particular choice and thus have the potential to reduce the social desirability bias (Hainmueller et al. 2015), which, as Milfont (2009) reported, is only a weak concern when measuring environmental behaviour. A negative aspect of the conjoint setup is that researchers define which elements are relevant and which are not; however, in the setup of the questionnaire I use in the present study, the research group closely followed the debate on the issue and is therefore confident that the setup covered the central factors.

To analyse the responses, I use models estimating the average marginal component effects (R package "cjoint", Hainmueller et al. 2014) and hierarchical linear regression models (Gelman and Hill 2007). Plots of the estimates present the results, and full result tables are available in the supplemental material.

\section{Data}

The trilingual survey ${ }^{3}$ on future energy provision in Switzerland collected 8,287 answers from a representative sample (provided by the Federal Office of Statistics) during the parliamentary debate on the energy law in spring 2016. Respondents received an invitation by post to participate in an online survey while parliament was drafting the policy. ${ }^{4}$ Later, in May 2017, citizens confirmed the policy solution the government and parliament drafted (Swiss Confederation 2016). The demographic and structural composition of the sample correspond quite closely to the Swiss population when compared to the full sample of potential respondents or the 2015 national election study (see supplemental material for discussion of the sample characteristics). The survey included two conjoint modules: respondents randomly answered one of the

\footnotetext{
3 The survey was administered in German, French, and Italian — the three most prominent of the four national languages of Switzerland. Respondents used the following languages: 65.4\% filled out the survey in German, 26.0\% French, and 8.6\% Italian. Romansh individuals used the German version.

4 The LINK Institute in Lucerne conducted the data collection process for the Institute of Political Science of the University of Bern. The Federal Office of Statistics provided the sample from the 'Stichprobenrahmen für Personenund Haushaltserhebungen' (SRPH). The collection period was March 2016 to mid-May 2016. The response rate after three invitations was $41.7 \%$.
} 
two, one of which I analyse here. From the 4,146 initial respondents, I excluded the fastest 5\% (210 respondents) due to their being 'speeders, ${ }^{5}$ which yielded a final sample of 3,936 respondents considered in the following analyses. As each individual responded to seven paired concepts, this results in $n=55,104$ responses $(7 \times 2 \times 3,936)$ which I will analyse.

\section{Measures}

The study focuses on the results of the conjoint experiment, whereby the main dependent variable is support for energy policy, measured on a scale from 0 to $100 \%$ in steps of $10 \%$, recoded as 0 to 10 in the analysis. The attributes of the conjoint experiment are the independent variables influencing this support. In other words, they are the treatments that serve as conditions or qualifications for respondents to either support or reject the policy. However, in addition to the results of the conjoint experiment, i.e. the support for the presented policies, the models consider several other variables for the analysis of opinion formation.

First, the present study measures systematic processing or opinion formation through the variance of responses per individual. Since each respondent stated his support for 14 policy proposals that varied randomly, those who consider policy information to form an opinion likely report varying support depending on the attributes of the policies - reacting to conditions which they rate more or less favourably. I consider within-individual treatment effects on support for policies and thus observed heterogeneity based on policy information as indications of systematic processing. The larger the individual variance in responses, the more the respondents reacted to stimuli and thus considered policy information in forming their opinion.

To evaluate how the processing of policy information varies by individual, the analysis considers the following characteristics. With respect to involvement, political interest and participation frequency serve as indicators of general involvement with pol-

\footnotetext{
5 'Speeders' answer the survey as quickly as possible and it is not guaranteed they actually consider the questions, i.e., they could be engaging in satisficing behaviour, which is also suggested by the lower heterogeneity in responses.
} 
itics. Moreover, I consider specific involvement through environmental beliefs (environmental protection and climate change scepticism), whereas more extreme responses on those scales represent higher issue-involvement (values further away from the middle point of the scale in either direction). Lastly, I include education to reflect knowledge, similar to Kriesi (2005). Unfortunately, there is no other measure reflecting specific political knowledge or efficacy in the survey. The left-right scale measures ideological predisposition, which positions individuals in the left, middle, and right of the political spectrum. The models further include control variables - i.e., language region, age (categorized), gender, and income (categorized). The supplemental material offers further detailed descriptions of all variables.

\section{Results}

Does support for energy policy depend on the specific design of a policy and thus on the policy information of a proposal? The opposite expectation would be that the design of a policy has no influence on support for policies, in which case one might expect that principally environmental attitudes would drive the support for and rejection of environmental measures (Bornstein and Thalmann 2008, Halbheer et al. 2006, Stadelmann-Steffen 2011). However, a bivariate comparison of support for the random policies presented to the respondents and their environmental attitudes shows that a favourable attitude toward the environment does not strongly predetermine support for all possible policies $(r=0.05)$. Rather, as Figure 1 shows, respondents with a high valuation of the environment (high scores on the $\mathrm{x}$ axis) also rejected policies deemed intolerable, while respondents with low scores on the same scale also supported some policies. Thus, policy design does matter - voters reject insufficient policies or those with controversial elements (i.e., keeping nuclear power plants up and running). The specific design of a policy is therefore a pivotal element in environmental decision-making; it explains why general attitudes and specific voting behaviour might diverge, which confirms the qualified support thesis (Bell et al. 2005). 


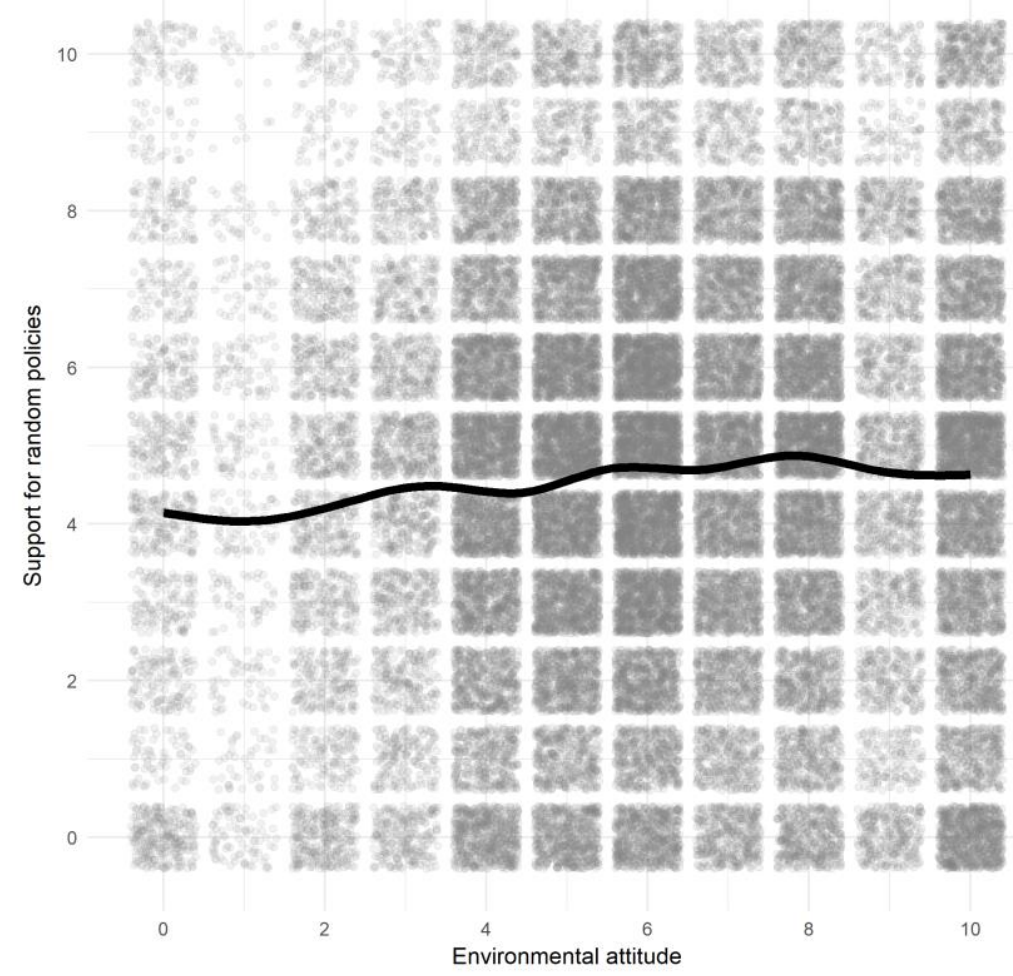

Figure 1. Support for policies and environmental attitudes. Line: smoothed conditional means with local polynomial regression fitting. Note: the figure represents jittered/scattered points to illustrate frequencies, i.e., the actual values are always full numbers.

\section{Influence of Policy Information on Support}

The question therefore arises as to what elements of a policy incite rejection and what elements increase support. To answer this, Figure 2 presents the average marginal component effects (AMCE, see Hainmueller et al. 2014) depicting the influence of the described policy attributes on the support for policies intended to promote renewable energies. Indeed, support is dependent on the design of the policy: high costs significantly reduce support, while explicitly prioritizing renewable energy (with an advantage of solar power and renewables in general) and including a provision for the shutdown of nuclear power plants have a positive effect on support. The policy measure, a quite technical provision of the policy, has no significant influence on support, which is similar to the source of funding, where the weak effects suggest a preference for energy-related taxes instead of general taxes. More administrative aspects - i.e., exceptions for energy-intensive industries (significant, but small marginal effect) and 
the sunset provision of the policy (nonsignificant) - also seem to lack salience in decision-making. However, in the first step of the analysis, the results corroborate previous research on voting on environmental measures by highlighting the relevance of costs in lowering support (Bornstein and Thalmann 2008, Halbheer et al. 2006, Thalmann 2004). For expectations about policy instruments, the results are less unambiguous, although respondents seem to prefer targeted tax measures over general income and value added taxes (Halbheer et al. 2006, Stadelmann-Steffen 2011). From the formulated assumptions, I accept hypothesis 1a on the negative influence of costs, while I reject hypothesis $1 \mathrm{~b}$ stating that policy instruments have an effect through perceived costs.

Conceptually, the results in Figures 1 and 2 corroborate the general expectation that the design of a policy has an influence on support as well as Bell et al.'s (2005) suggestion that support is conditional on the specifics of a proposal. Indeed, compared to Hainmueller et al. (2015), qualifications seem more influential in environmental questions than in ballot decisions on naturalization of immigrants. Moreover, ex ante assumptions about which qualifications are relevant for people are difficult. The policy measure, for example, which defines the promotion of renewable energy technologies, does not seem to be relevant for individuals, although policymakers would likely consider this aspect of the policy to be highly relevant since it defines how the state intervenes in the economy. Two main conclusions are thus possible. First, the results confirm the multidimensional decision-making process; several aspects of a policy are relevant for decision-making rather than only individual aspects of information. Research on environmental decisions should thus include the details of a policy if the researchers want to obtain more valid responses from citizens, addressing the issue of qualified support (Bell et al. 2005), and getting closer to actual judgment situations (Dermont et al. 2017). Indeed, individuals do reach decisions based on the elements of a policy and systematically process the policy information presented to them in the analysed experiment (Boudreau and MacKenzie 2014, Bullock 2011). Second, it is necessary to consider varying types of policy information rather than only economic aspects (such as costs), policy instruments (such as the type of tax), and administrative 
questions (such as exceptions). Related policies, illustrated by the salience of the provision on nuclear power in a policy targeted at renewable energies, and soft factors, such as which renewable energy source policymakers prioritized, influence decisionmaking. The latter also highlights how positive aspects can serve as a 'selling point' in policymaking when combined with less favoured provisions.

\section{Individual Characteristics and Opinion Formation}

Is it possible to determine which individuals react to policy details and discriminate more in their policy support? From a theoretical point of view, an answer to this conundrum would identify which individuals engage in systematic processing and are therefore qualified supporters in the field of environmental politics.

In Switzerland, involvement in politics and attitudes about issues increases systematic processing (Kriesi 2005, Nai 2010). In the experimental setup, I consider individuals who reacted to the policy information and reported varying support in the 14 repeated tasks as engaging in systematic processing. Within-individual variance of support indicates that individuals react to the treatments in the different tasks, as the displayed attributes vary in each task. The more variance in support a respondent reports, the more she reacts to the policy information treatment and considers elements of a policy as qualifications that lead to higher or lower support of a (hypothetical) policy. For low variance, there are two possible explanations. First, individuals persistently support the status quo (reject all policies) or any change (support all policies) and thus report very similar support regardless of the design. Second, individuals who are less involved with the issue or politics in general resort to less engaging responses that do not reflect the design of the presented policies. 


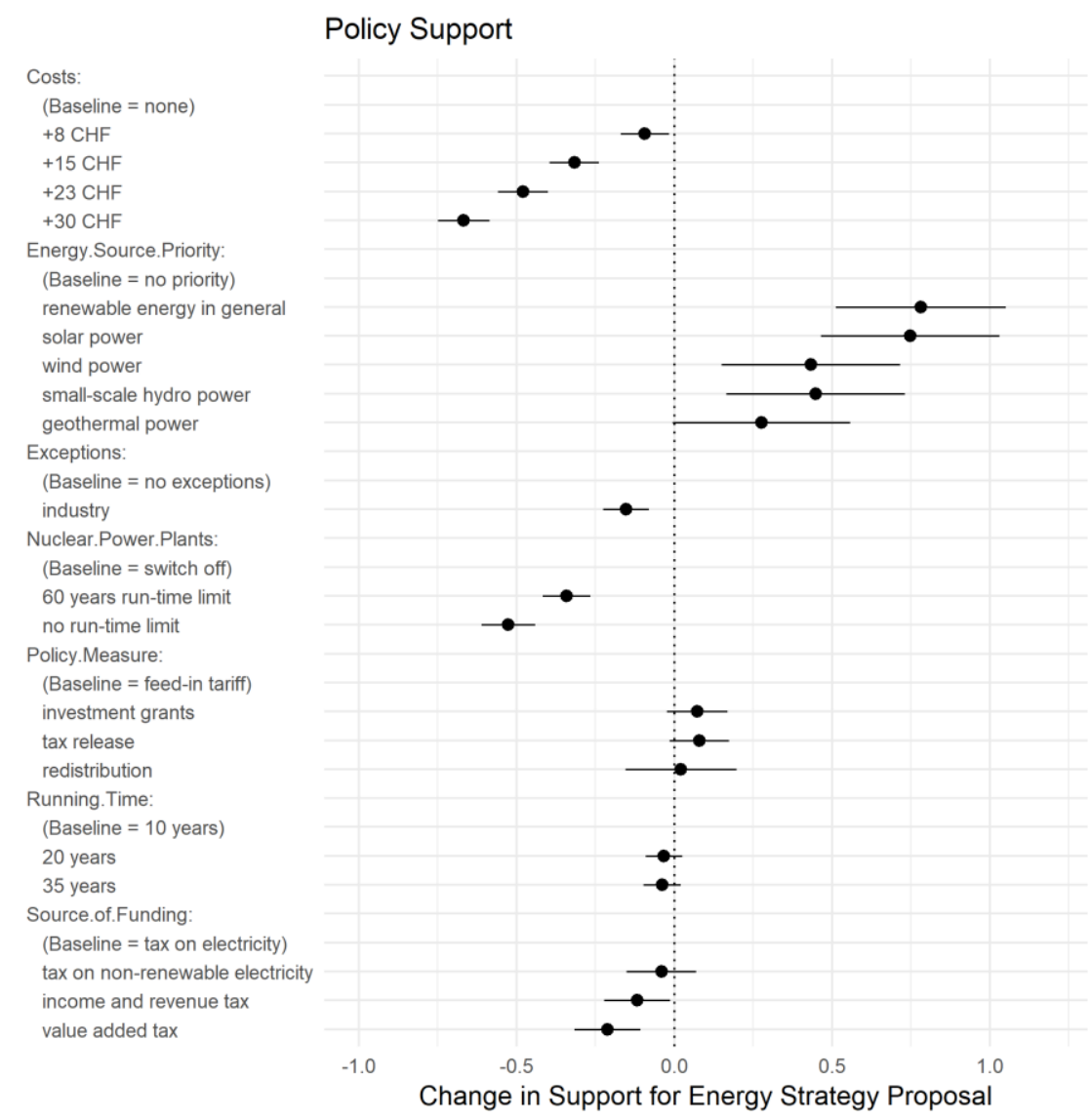

Figure 2. Model 1, Average Marginal Component Effects (mean and 95\% confidence interval, Hainmueller et al. 2014) of policy details on support for energy policy (DV). Reading example: Support for a policy including additional costs is for all values rated lower than a policy without additional costs. A raise in 23 Swiss Francs is therefore in average changing support by -0.5 points on a scale from 0 to 10 . Notes: clustered standard errors, line ranges denote 0.95 confidence intervals, $\mathrm{CHF}=$ Swiss Francs (approx. 1US\$). The supplemental material provides full results.

Initially, the variance of support per respondent suggests substantial within-individual treatment effects in responses. In statistical terms, the mean standard deviation is 2.03 , and the mean variance is 5.32 (on a scale from 0 to 10; refer to the supporting material for further analyses and figures). In order to observe whether this variance is explainable, Figure 3 presents the results of two standard linear regressions. As dependent variables, I use two measures of heterogeneity: distance (the difference between the highest and lowest reported support, reflecting how respondents used the scale) and the individual standard deviance of support. The independent variables are 
involvement with politics and the issue at hand as well as demographic characteristics, as described in the measures section. The estimates thus reflect how individual characteristics correlate with more variation in support for environmental measures.

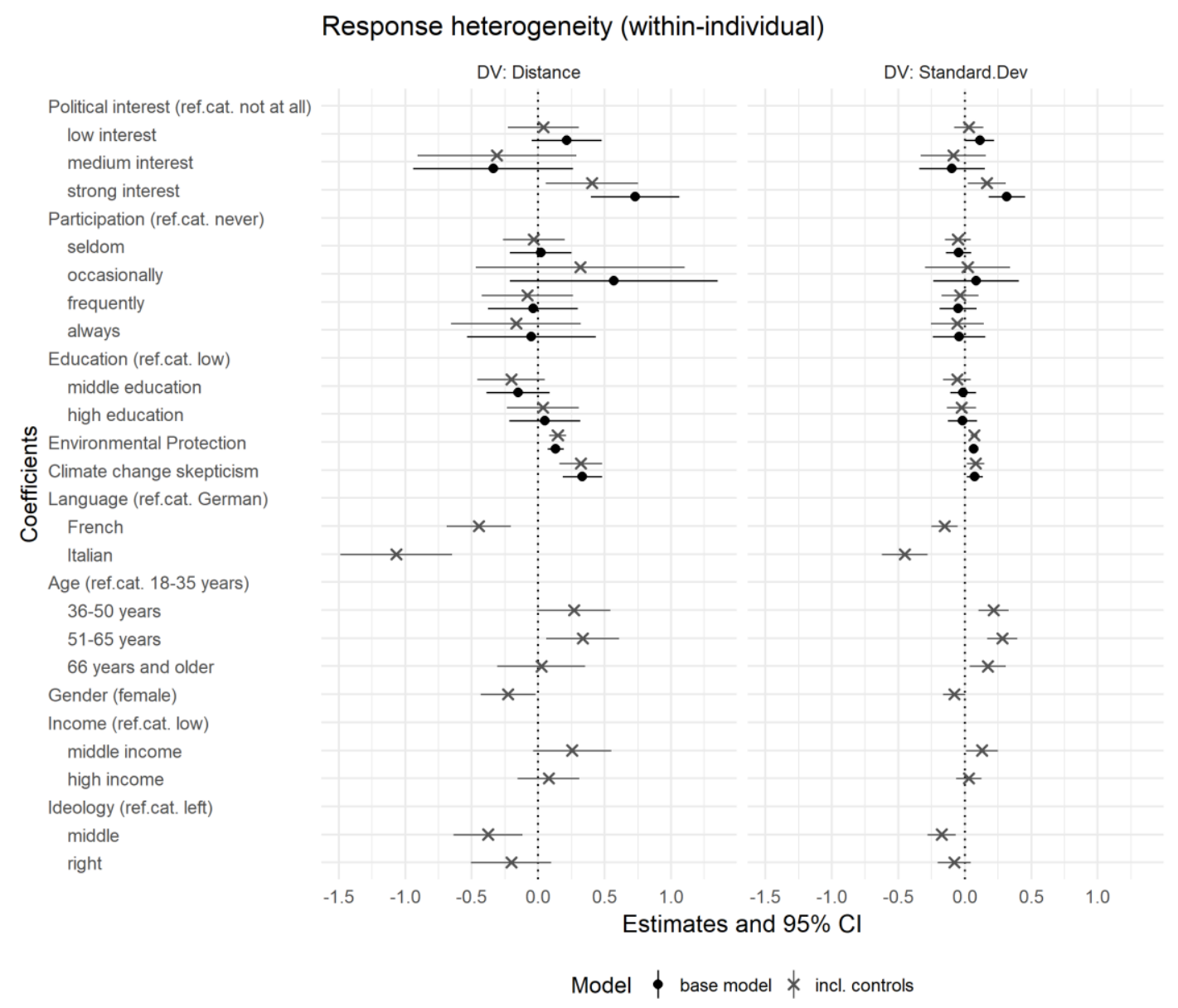

Figure 3. Models 2 and 3, hierarchical linear models estimating response heterogeneity for distance and standard deviance as dependent variables, repeated observations nested within individuals. Reading example: Both with and without control variables in the model, individuals with high political interest have a higher heterogeneity as denoted by the point estimate and the line range (0.95 confidence interval). Note: the supplemental material provides full results.

Both with and without individual control variables, respondents with a strong interest in politics and who have more polarized attitudes on the issue at hand are more likely to engage in systematic processing based on the policy details presented to them. ${ }^{6}$ However, the results also showed that, contrary to expectations, education and

\footnotetext{
${ }^{6}$ Most importantly, the significant effect of strong prior attitudes leading to more heterogeneity in support eliminates the speculation that strong attitudes could lead to accepting or rejecting everything. In contrast, the results indicate that respondents with strong attitudes differentiate more and therefore are more critical and susceptible to qualifications.
} 
frequent political participation do not influence individual variance. In addition, the results show that language region (i.e., cultural aspects) and age influence the variance of support and that women report less varying support than men.

In other words, individuals with high involvement with an issue are particularly attentive to policy information. This corroborates previous findings on specific involvement (Chaiken 1980, Kriesi 2005, Nai 2010); however, general involvement with politics and education is not unequivocally related to more systematic processing. I therefore reject Hypothesis 2a, although the results offer support for the aspect of specific issue involvement leading to more systematic processing, which suggests that qualified supporters are primarily those individuals concerned about the issue at stake.

Since environmentally concerned respondents are more engaged with the decisionmaking situation than others, the question arises as to whether the marginal effects of policy details are consistent for all individuals or whether they vary according to individual characteristics. Based on the results of models 2 and 3, strong political interest and strong opinions on climate change and environmental protection seem to be the driving factors of more involvement with policy proposals and thus of systematic processing. Therefore, for each of these three characteristics, Figure 4 includes an interaction effect, i.e. Conditional AMCE (Hainmueller et al. 2014). ${ }^{7}$ Additionally, a split of left, middle, and right across the political spectrum enables the observation of ideological differences.

${ }^{7}$ With respect to political interest, I separate the sample into strong interest and all the lower levels of political interest; with respect to attitudes toward climate change and environmental protection, I use the median to split the sample into two groups. 


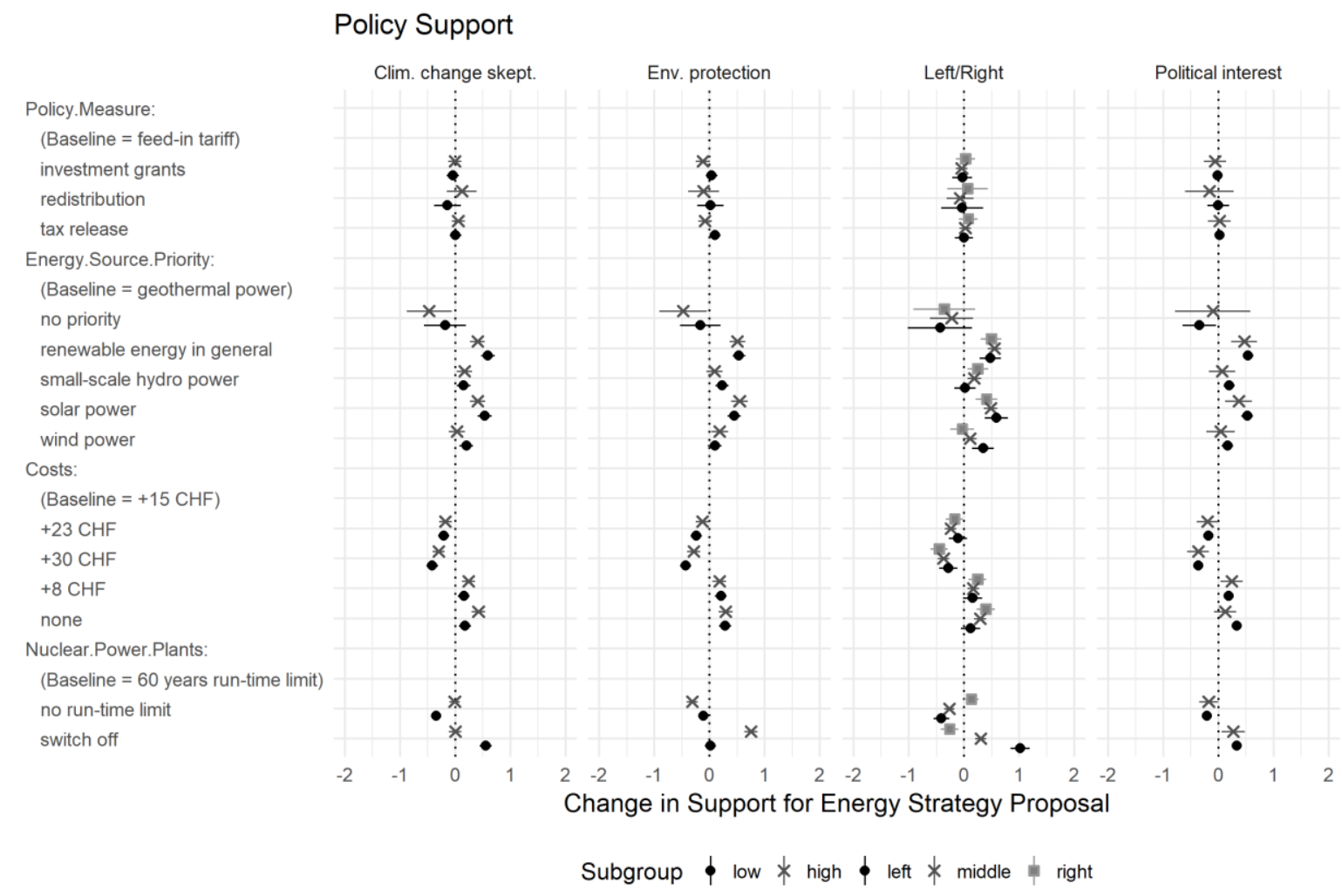

Figure 4. Model 4, Conditional Average Marginal Component Effects (mean and 95\% confidence interval, Hainmueller et al. 2014) of selected policy details on support for energy policy (DV) with interaction effects for climate change scepticism, environmental protection attitudes, political interest, and political ideology. Notes: clustered standard errors, line ranges denote 0.95 confidence intervals, CHF = Swiss Francs (approx. 1US\$). The supplemental material provides full results.

While the conditional marginal effects are predominantly consistent throughout the different categories included as interaction effects, the most obvious difference by subgroup is in the treatment of nuclear power plants. With respect to this policy aspect, not limiting the run-time of nuclear power plants only significantly lowers the support of individuals who are convinced that climate change is humanly induced or who prefer environmental protection rather than the use of nature's resources. For rightwing citizens, the effect is the opposite: not restricting nuclear power leads to higher support. Also, in contrast to the citizens who care about climate change, citizens who are sceptical about climate change do not systematically discriminate according to which energy source a policy measure prioritizes. A similar picture is observable for political interest, which highlights the differences in certain subgroups' consideration of policy information. 
Hypotheses $2 \mathrm{~b}$ and $2 \mathrm{c}$ anticipated that lower involvement would moderate the effects of certain attributes on policy support. However, as the marginal effects are largely consistent across groups for costs and the policy instrument, I reject the hypotheses. Low involvement does not lead to a stronger effect of costs on support, and policy measures are not more salient for individuals with high involvement.

Nevertheless, the differences in attitudes and political interest show how some policy details are more relevant for subgroups, albeit not the details that previous related research suggest. In contrast, Figure 4 shows that differences in preferences are relevant for two aspects of environmental measures that the public regularly discusses: nuclear power plants and the new renewable energy technologies toward which the public expresses greater acceptance.

\section{Conclusion}

In this analysis, I investigated how public support for energy policy depends on the specific design of a policy. Specifically, using a conjoint experiment for simulation purposes, I examined how voters consider detailed policy information in environmental decision-making. In summary, the analysis illustrates that citizens do indeed consider policy information in forming their opinions. Providing voters with the specifics of a proposal allows us to analyse which elements of a policy incite opposition among voters who would generally be in favour of a target (Bell et al. 2005), while individuals who are more concerned with the environment and climate tend to react to such qualifications. The results suggest that costs are particularly influential, while policies toward the promotion of new renewable energy sources still closely link to nuclear power. The specific type of policy instrument used to promote renewable energies, in contrast, seems less salient in individual decision-making.

The results show that policy design is a pivotal element of evaluation of policies. Just because an individual is generally in favour of environmental protection does not automatically lead to support for any promotional measures for renewable energies (Bell et al. 2005, Dermont et al. 2017). The results demonstrate that citizens consider the 
presented policy information when making decisions, which illustrates that unfavourable aspects of a policy that do not meet the conditions that individuals set for supporting a policy cause the gap between general attitude and specific voting behaviour (Bell et al. 2005). Moreover, from a conceptual point of view, it is both possible and necessary to provide respondents with varied policy information, as it reflects the multidimensional character of decision-making and allows respondents to focus on the aspects they consider relevant. As Mondak (1994, p. 170) pointed out, the 'contexts in which actual political judgements are made differ from the isolation of the laboratory'. Presenting respondents with only one policy detail or a few vague aspects of a policy suggests an artificial information environment where citizens are not exposed to contradictory information. Giving individuals comprehensive information about policies in surveys and allowing them to decide on which aspects of these policies they want to focus better reflects the context of decision-making and campaigns in direct democracy, thus leading to more valid results and insights into public opinion.

This more substantiated approach of a conjoint experiment, as distinct from those of Bullock (2011) and Boudreau and MacKenzie (2014), provides a more thorough account of the use of policy information and the relevance of policy design in forming an opinion. It therefore offers more detailed feedback on public preferences for policymakers designing future policies that need public support. Insights into acceptance of renewable energies specifically and new technologies generally are thus more valid if researchers present respondents with comprehensive information, and include, especially, possible negative conditions of policies that might incite opposition.

However, several questions remain. Most importantly, this analysis has not considered alternative paths of decision-making besides systematic processing. For instance, it did not consider heuristics such as party cues or attempt to include local, social and personal determinants or consequences in the analysis. Moreover, the debate in Switzerland on renewable electricity and nuclear power plants is ongoing. Researchers should consider the campaign before a vote to arrive at a more comprehensive overview of policy information and its effect on opinion formation in environmental policy (Bolsen et al. 2015, Chong and Druckman 2007, Kriesi 2012). Lastly, researchers should implement conjoint experiments in other countries with similar and divergent settings 
to assess the generalizability of the results from a strong direct-democratic country such as Switzerland. Also, confirming or rejecting the results with other political issues would enable a clearer assessment of the external validity of the results.

Although this study prompts the need for further research, the use of a multifacto-

rial survey experiment to research voters' behaviour has advantages compared to more traditional approaches of voting research generally. Primary among these advantages is that multifactorial results capture decision-making and reasoning in a more nuanced way. I have therefore described a suitable approach to address the puzzle of social acceptance as a substantial hurdle to the success of policies and for the understanding of individual behaviour.

\section{Acknowledgements}

I thank James N. Druckman, Isabelle Stadelmann Steffen, Ulf Liebe and Anja Heidelberger for their valuable advice, two anonymous reviewers and the editors of Environmental Politics for insightful comments and directions for improvement, as well as panel participants at the 2017 MPSA Conference, the 2017 SPSR Conference and the 2016 ECPR General conference for their helpful comments. The Swiss National Science Foundation (National Research Programme "Managing Energy Consumption", NRP71) and the IMG Foundation supported this research. 


\section{References}

Altman, D., 2010. Direct democracy worldwide. Cambridge: Cambridge University Press.

Bayulgen, O., and Ladewig, J. W., 2017. Vetoing the future: political constraints and renewable energy. Environmental Politics, 26 (1), 49-70.

Bechtel, M. M., and Scheve, K. F., 2013. Mass support for global climate agreements depends on institutional design. Proceedings of the National Academy of Sciences of the United States of America, 110 (34), 13763-13768.

Bell, D., Gray, T., and Haggett, C., 2005. The 'social gap' in wind farm siting decisions: explanations and policy responses. Environmental Politics, 14 (4), 460-477.

Bell, D., et al., 2013. Re-visiting the 'social gap': public opinion and relations of power in the local politics of wind energy. Environmental Politics, 22 (1), 115-135.

Bernardi, L., et al., 2018. The effects of the Fukushima disaster on nuclear energy debates and policies: a two-step comparative examination. Environmental Politics, $27(1), 42-68$.

Bolsen, T., Druckman, J. N., and Cook, F. L., 2015. Citizens', scientists', and policy advisors' beliefs about global warming. The Annals of the American Academy of Political and Social Science, 658 (1), 271-295.

Bornstein, N., and Lanz, B., 2008. Voting on the environment: price or ideology? Evidence from Swiss referendums. Ecological Economics, 67 (3), 430-440.

Bornstein, N., and Thalmann, P., 2008. 'I pay enough taxes already!' Applying economic voting models to environmental referendums. Social Science Quarterly, 89 (5), 1336-1355.

Boudreau, C., and MacKenzie, S. A., 2014. Informing the electorate? How party cues and policy information affect public opinion about initiatives. American Journal of Political Science, 58 (1), 48-62.

Bullock, J. G., 2011. Elite influence on public opinion in an informed electorate. American Political Science Review, 105 (3), 496-515.

Chaiken, S., 1980. Heuristic versus systematic information processing and the use of 
source versus message cues in persuasion. Journal of Personality and Social Psychology, 39 (5), 752-766.

Chong, D., and Druckman, J. N., 2007. Framing public opinion in competitive democracies. American Political Science Review, 101 (4), 637-655.

Colombo, C., and Kriesi, H., 2017. Party, policy-or both? Partisan-biased processing of policy arguments in direct democracy. Journal of Elections, Public Opinion and Parties, 27 (3), 235-253.

Deacon, R., and Shapiro, P., 1975. Private preference for collective goods revealed through voting on referenda. The American Economic Review, 65 (5), 943-955.

Dermont, C., et al., 2017. Bringing the policy making perspective in: a political science approach to social acceptance. Energy Policy, 108, 359-368.

Devine-Wright, P., 2005. Beyond NIMBYism: towards an integrated framework for understanding public perceptions of wind energy. Wind Energy, 8 (2), 125-139.

Eagly, A. H., and Chaiken, S. 1993. The psychology of attitudes. Fort Worth, TX: Harcourt Brace Jovanovich College Publishers.

Gelman, A., and Hill, J., 2007. Data analysis using regression and multilevel/hierarchical models. New York: Cambridge University Press.

Hainmueller, J., Hangartner, D., and Yamamoto, T., 2015. Validating vignette and conjoint survey experiments against real-world behavior. Proceedings of the $\mathrm{Na}-$ tional Academy of Sciences of the United States of America, 112 (8), 2395-2400.

Hainmueller, J., Hopkins, D. J., and Yamamoto, T., 2014. Causal inference in conjoint analysis: understanding multidimensional choices via stated preference experiments. Political Analysis, 22 (1), 1-30.

Halbheer, D., Niggli, S., and Schmutzler, A., 2006. What does it take to sell environmental policy? An empirical analysis of referendum data. Environmental \& Resource Economics, 33 (4), 441-462.

Häusermann, S., Traber, D., and Kurer, T., 2015. Altersvorsorge 2020. Intakte Erfolgschancen trotz starkem Widerstand gegen Sparmassnahmen. Zürich: Universität Zürich.

Hobman, E. V., and Ashworth, P., 2013. Public support for energy sources and related technologies: the impact of simple information provision. Energy Policy, 63, 
862-869.

Kahn, M. E., and Matsusaka, J. G., 1997. Demand for environmental goods: evidence from voting patterns on California initiatives. Journal of Law and Economics, 40 (1), 137-173.

Kollmuss, A., and Agyeman, J., 2002. Mind the gap: why do people act environmentally and what are the barriers to pro-environmental behavior? Environmental Education Research, 8 (3), 239-260.

Kriesi, H., 2005. Direct democratic choice: the Swiss experience. Lanham: Lexington.

Kriesi, H., 2012. Political communication in direct democratic campaigns: enlightening or manipulating? Basingstoke: Palgrave Macmillan.

McDermott, R., 2011. Internal and external validity. In: J. N. Druckman, D. P. Green, J. H. Kuklinski, and A. Lupia, eds. Cambridge handbook of experimental political science. Cambridge: Cambridge University Press, 27-40.

Milfont, T. L., 2009. The effects of social desirability on self-reported environmental attitudes and ecological behaviour. The Environmentalist, 29 (3), 263-269.

Mondak, J. J., 1994. Question wording and mass policy preferences: the comparative impact of substantive information and peripheral cues. Political Communication, $11(2), 165-183$

Nai, A., 2010. Processus cognitifs et formation de l'opinion dans les votations fédérales (1999-2005): une analyse multiniveaux. Thesis (PhD). University of Geneva.

Petty, R. E., and Cacioppo, J. T., 1986. The elaboration likelihood model of persuasion. In: R. E. Petty and J. T. Cacioppo, eds. Communication and persuasion. New York: Springer, 1-24.

Stadelmann-Steffen, I., 2011. Citizens as veto players: climate change policy and the constraints of direct democracy. Environmental Politics, 20 (4), 485-507.

Swiss Confederation, 2016. Energiegesetz (EnG). Bundesblatt, 40, 7683-7730.

Szulecki, K., 2018. Conceptualizing energy democracy. Environmental Politics, 27 (1), 21-41.

Thalmann, P., 2004. The public acceptance of green taxes: 2 million voters express their opinion. Public Choice, 119 (1-2), 179-217.

Tsebelis, G., 2002. Veto players: how political institutions work. New York: Russel Sage. 
van Rijnsoever, F. J., van Mossel, A., and Broecks, K. P. F., 2015. Public acceptance of energy technologies: the effects of labeling, time, and heterogeneity in a discrete choice experiment. Renewable and Sustainable Energy Reviews, 45 (5), 817-829.

Wüstenhagen, R., Wolsink, M., and Bürer, M. J., 2007. Social acceptance of renewable energy innovation: an introduction to the concept. Energy Policy, 35 (5), 26832691.

Wu, X., and Cutter, B., 2011. Who votes for public environmental goods in California? Ecological Economics: The Journal of the International Society for Ecological Economics, 70 (3), 554-563. 


\section{Appendix}

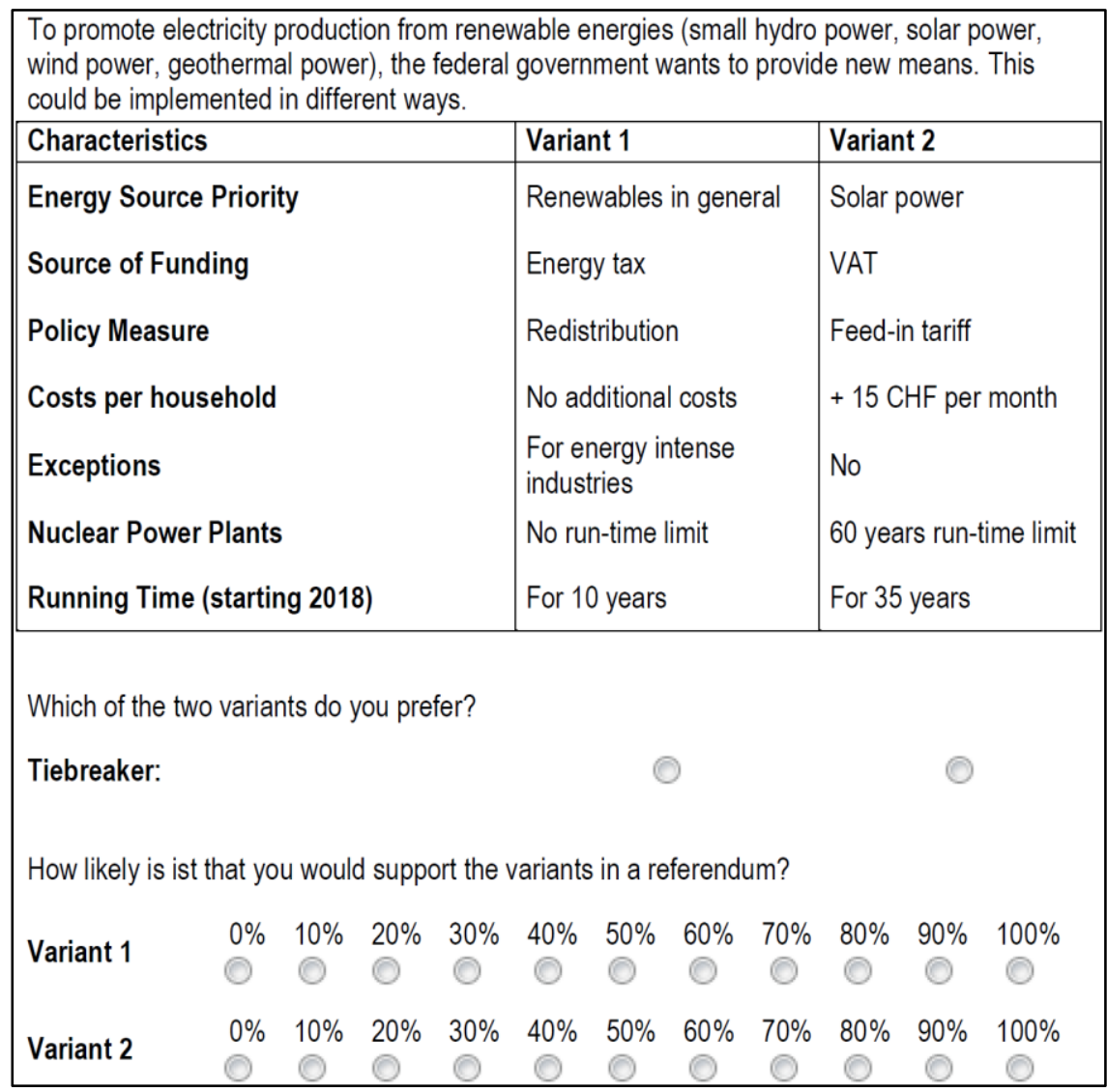

Figure A1. Experimental Design: Exemplary setup of the question with the choice and support answers. For each respondent, attribute order was randomized, and for each repeated presentation the attributes displayed were randomized individually, i.e., no respondent received the identical version of the experiment. Note: description of the attributes in the supplemental material. 